ORIGINAL ARTICLE

\title{
Patients' experiences of an open access follow up arrangement in managing inflammatory bowel disease
}

\author{
A Rogers, A Kennedy, E Nelson, A Robinson
}

Qual Saf Health Care 2004;13:374-378. doi: 10.1136/qshc.2003.008292

See end of article for authors' affiliations

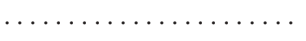

Correspondence to: Professor A Rogers, National Primary Care Research and Development Centre, The University of Manchester, Manchester M13 9PL, UK; anne.rogers@man.ac.uk

Accepted for publication 22 June 2004

\begin{abstract}
Background: Improving access is a key policy issue in improving quality of care and extending patient choice and participation. People's experience of changing from fixed outpatient appointments to more flexible direct access arrangements for chronic disease has been underexplored.

Objectives: To examine patients' views on using an open system of access compared with fixed outpatient appointments as part of a guided self-management intervention for inflammatory bowel disease (IBD).

Design: Embedded qualitative study undertaken alongside a randomised controlled trial. Semi-structured interviews were undertaken to obtain an in depth understanding of patients' experience of the change in access arrangements.

Participants: A purposive sample $(n=30)$ was drawn from the intervention group $(n=700)$ according to a range of responses to the trial baseline and follow up quantitative measures.

Results: 28 interviews were included in the analysis. Compared with the previous system of fixed appointments, preference for the new open access system was based on enhanced personal control in contacting services and the view that it fitted better with everyday routine management and the requirement for urgent medical contact when symptoms fail to respond to medication. Preference for retaining fixed appointments was based on a sense of security from gaining access which did not require the individual to initiate the request for medical help.

Conclusions: Open access may fit better with patients' self-management of their condition and everyday routines, roles and responsibilities. Ensuring that outpatient organisational arrangements and personnel are responsive to patient initiated requests for appointments is likely to impact on the acceptability of this type of access arrangement. Some people may continue to prefer the fixed appointment system which should be retained if patient choice is to be respected.
\end{abstract}

Inflammatory bowel disease (IBD) is used as an exemplar of a chronic disease to explore patient response to open access arrangements introduced as part of an intervention which was evaluated by a randomised controlled trial (RCT). Crohn's disease and ulcerative colitis affect about 175000 people in the UK. ${ }^{8}$ Current medical treatment is ameliorative rather than curative and many patients need maintenance drug treatment. Symptoms-which include bloody diarrhoea, abdominal pain and weight loss-follow a relapsing course with periods of remission. The RCT to which this study is linked is outlined in box 1.

Variations to traditional outpatient department access arrangements for IBD have been tested in two studies. A recent randomised trial explored the effectiveness of using the general practitioner (GP) as the first point of contact which reduced demand for outpatient attendance. ${ }^{9}$ Patients randomised to follow up through open access were asked initially to contact their GP about problems and were only encouraged to contact the hospital directly if they were unable or unwilling to see the GP first. However, this link with primary care may be unnecessary given, as the second study suggests, it is likely that secondary care services provide principally for the ongoing contact people have with a chronic illness such as IBD. ${ }^{10}$ Neither of these studies was able to identify and account for the processes underlying the fall in the number of outpatient appointments.

This study was undertaken to examine the experiences and views of patients with IBD on their use of a new system of open access to outpatient clinics compared with the traditional system of fixed appointments and to determine the rationale behind their preference. specialities ${ }^{7}$ ) or lack of access for those in need of urgent attention.

(1) 


\section{Box 1 Inflammatory bowel disease RCT}

The intervention was an evidence based package designed to bridge the gap between the requirement for continuity of clinical care and a patients' own requirements for disease management ${ }^{17}$ (evidence suggests that patients with IBD feel insufficiently informed and want involvement in their treatment ${ }^{18}$ ). The RCT had two arms and outcome measures were recorded at baseline and at 12 months. The intervention had four components:

Improved information

Provision of a patient guidebook containing information that is relevant, accessible and uses a combination of lay and traditional evidence based knowledge. Guidebooks for ulcerative colitis $^{19}$ and Crohn's disease ${ }^{20}$ were developed with patients before the study. ${ }^{21}$

\section{Guided self-management}

A written guided self-management plan to which patients can refer when making decisions about treatment and the need for service contact. ${ }^{10}$

\section{Changed professional response}

Promote flexibility in professional response through a patient centred approach provided by consultants trained in its methods.

\section{Changed access to services}

Provide direct access to services, allowing and enabling patients to self-refer based on their own evaluation of need. ${ }^{22}$

The objective of our study was to determine whether this "whole systems approach" - which includes interventions at a number of levels (the patient, the professional method of working, and the organisation of services)-altered patients' abilities to self-manage their condition, and whether they made more appropriate use of health service resources. The main results of the trial are reported elsewhere. ${ }^{16}$ Three outcome measures used in the trial provide the context for the qualitative analysis of the open access arrangements. These were: the number of appointments attended during the trial year; the number of made appointments not attended; and the percentage of patients who self-referred.

The number of appointments reduced by approximately one third in the intervention group (from 3.0 to 1.9) compared with the control group (from 3.1 to 3.0; difference $-1.04,95 \% \mathrm{Cl}-1.43$ to $-0.65, \mathrm{p}<0.001)$. The number of non-attendances during the trial was also lower for the intervention group than for the control group (difference $-0.08,95 \% \mathrm{Cl}-0.15$ to $-0.01, p=0.034)$. More patients at intervention centres than at control centres self-referred for at least one appointment $(43 \% \vee 22 \%, p<0.001)$.

At the end of the trial patients recorded whether they would prefer traditional fixed hospital appointments or the intervention system where they receive a personal selfmanagement plan and can make their own appointments. Analysis was restricted to the intervention arm. Overall, 26\% of patients in this arm expressed a preference for the traditional system and $74 \%$ expressed a preference for the open access arrangements. We concluded that changing access arrangements was generally acceptable to most patients with IBD and reduced demand for health service resources. ${ }^{16}$

\section{METHODS}

To extend and challenge the existing data and test the integrity of the findings from the main trial, we used aspects of grounded theorising to guide the sampling, collection, and analysis of qualitative data. ${ }^{11}$ Qualitative semi- structured interviews were undertaken to obtain an in depth understanding of patients' experience of the intervention and to focus on the processes underlying the outcomes of the trial. Interviews were conducted by EN and took place between January 2001 and July 2001. All interviews were audiotaped, lasted 30-60 minutes, and were transcribed verbatim.

A purposive sample of 30 respondents was drawn from the intervention group according to a range of responses on the trial baseline and follow up quantitative measures to reflect the range of possible experiences underlying responses to the changing self-management and health service arrangements. A checklist of topics was initially generated by the research team and modified in an interactive and iterative fashion after initial interviews. Agreement around meaning was established through regular discussions and comment throughout the interviewing, collection, collation, and analysis of interviews (EN, AK, AR). This ensured the key areas of having participated in the trial were comprehensively covered with each respondent while, at the same time, allowing issues which were important to patients to emerge. The latter was consistent with a phenomenologically informed approach to thematic analysis aimed at exploring the interpretive meanings given to access arrangements.

Interviewing ceased after 30 interviews as there were no new themes arising and repetition of accounts indicated saturation of the existing themes. Similar themes across interviews were identified and within or sub-themes scrutinised in depth. The NUDIST qualitative data analysis system ${ }^{12}$ was used to assist with the thematic analysis which involved examining the interviews thematically across the whole dataset as well as in the context of each patient's account in relationship to patients' perceived satisfaction with the intervention as a whole. The results of the thematic analysis were described under broad headings and illustrated with extracts from the most relevant interviews. This included the personal and social context of managing illness and coping strategies before the intervention and perceptions about patient experience of each component of the intervention (guidebook, patient consultation, and access arrangements) and overall impact on self-management and health behaviour.

Here we report only what was said or is relevant to the open access arrangements, which included the experience of negotiating the type of appointment system to be used, subsequent use of the arrangements compared with previous access arrangements, and perceptions and evaluation of intermediary processes-for example, contact with secretarial staff and receptionists in outpatient departments.

Twenty eight of the 30 respondents in our sample discussed the open access arrangements for making appointments (two did not articulate an elaborated response when asked about this area of their experience). They included six respondents who were offered open access but subsequently renegotiated or reverted back to the fixed appointment system. The information gleaned from these later interviews together with the accounts given by all the respondents who had previously used the fixed appointment system allowed comparisons to be made between fixed appointments and open access.

\section{RESULTS}

Of the 28 respondents, 17 had ulcerative colitis (UC), 11 had Crohn's disease (CD), 16 were female, 17 were in employment, and their ages ranged from 22 to 68 years.

\section{Comparison of direct access with fixed appointments} Judgement about the new access arrangements was formed against the backdrop of people's previous experiences of a system of making and attending fixed regular appointments over a number of years. Previous attendances at outpatient 
departments were frequently portrayed as personally inconvenient, wasteful of time, and ineffective organisationally.

"I think the waiting has got worse, it used to be quite quick really. But sometimes I wait ages and an hour and a half is a nuisance when you are busy and have young children" (UC, female, age 36)

"The waiting time can be long, but you expect that. Generally you go with the knowledge that you can be a long time" (laughter) (UC, male, age 46)

Consideration of the specific difficulties faced by people with IBD in attending and the inconvenience relative to the perceived importance of what was undertaken during the appointment was also relevant.

"The clinic for Crohn's is in the morning, now people with Crohn's have very bad mornings getting up, dealing with toilets and getting down there. They have sent me appointments for 9 o'clock in the morning and I just found it stupid that all these people with bowel disorders are having to go to morning clinics. And when I've sort of said -oh the later the better - they say what about 10 o'clock and I say can you just pass it on a bit later-and they look at you as if you're stupid so now I just tell them 'look I've got Crohn's disease and I can't get out of the bathroom for at least 3 hours... I hate to think of how the people manage who have to get there for 9 o'clock..." (CD, female, age 29)

"Oh it's been a nightmare-honestly—especially when I took the children, because sometimes I've had to take the both of them...They don't do anything they just ask you how you're going on and give you the medicine and the blood tests. I go every six months" (UC, female, age 53)

\section{Link between increased sense of control in managing IBD and increased satisfaction in using open access}

The qualitative data suggested that a preference for the open access system was based on more than a predilection for a less inconvenient system. The new access arrangements seemed to signify a transfer of control in using services from the hospital to the individual which, in part, was also linked to people's confidence in their ability to manage their own condition. The form of advice and support which replaced the fixed routine outpatient appointments fitted better with the individual ways in which people managed and coped on an everyday basis with their chronic illness which had been encouraged by the new approach.

"It was clear to me that I could ring to make an appointment or to chat. I thought that was a good idea because if you are managing your own life-like I'm used to anyway - a lot of the time you're wasting time going back to the hospital." (CD, female, age 60)

"It's been very good for me because when you are running your own business you don't want to be nipping down to the hospital all the time-not if you don't need to. This is definitely how I would like to carry on-definitely. I like the flexibility of this, it suits my life and I am happy to deal with the flare-ups. I'm fortunate, I don't seem to have that much I need to worry about. It's just an illness and you have to treat it as such." (UC, male, age 43)

A sense of autonomy in deciding when and how to use hospital outpatient resources was reinforced by the knowledge that the service was there when and if it was needed. In addition, some people felt they were getting a better service even if contact with services was less, because the system was felt to map more closely onto people's own needs rather than the person having to fit in with the organisational imperatives of the hospital system.

"I feel more in charge of my condition. I know that the safeguard (the phone) is there should I need it and I prefer this to having standard appointments. I share the decisions with him and I am prepared to take the responsibility for myself. Previously, as I said, the condition was managed for me and I was told what to do... And it then became not something that controlled me but something that I can live with and control so that it doesn't affect my life." (UC, male, age 46)
"I haven't needed to use it. But I do have a vague recollection of him (the doctor) saying ring me and come in if you get any flare-ups like this again and I found that quite reassuring and [that] I wouldn't [have to] lie in bed like I have before and suffer and do nothing -I wouldn't hesitate to ring if I was ill again..." (UC, female, age 40)

Responses to the open access arrangement suggested that people saw it as fitting in with future long term management based on the other parts of the approach which made up the whole systems approach (see box 1). Increasing people's confidence and ability to manage was consciously built into the design of the guided self-management information, with the idea of reinforcing this through evidence of introducing self-management and trying to reinforce it through the philosophy of patient centred consultations and greater freedom in using open access arrangements.

"I would like it to proceed exactly as it is ... that if I need to see him then I want to be able to pick up the phone and say 'things are not going well and I need a consultation' and to be able to have one in quite a short space of time. Whether that would work I don't know because I've never had to do it since the project started, but that's how I would see it in an ideal world." (UC, male, age 60)

"I prefer to make my own appointments. I thoroughly agree with this whole management system because, if you keep coming back every 6 months, you might have a flare-up in the middle and be fine when your appointment comes, so what's the point? You need them to see you when you've got symptoms. I think it's an excellent idea and it certainly works for me. I phoned on the Friday and I was in on a Thursday and I was quite happy with that. You need to have early access because you need to phone when you have a problem ..." (CD, male, age 40)

The new arrangements were usually viewed as the intended outcome of negotiation and sense of trust and equality between doctor and patient which underlies the patient centred consultation training. Surprise was occasionally expressed when the new access arrangements were actually found to work:

"I did phone up once in the beginning when I had a couple of problems -I phoned his secretary and he actually did phone me back at work." (UC, male, age 43)

The personal benefits of the open access arrangements were not seen in isolation. Rather, evaluations were made with reference to a collective responsibility towards the NHS. In the following quotation clear reference is made to being treated well in the context of overstretched services.

"I felt I got a lot of support from him, especially the fact that he gave me his secretary's telephone number .... with the words if at any time you want to get in touch phone my secretary and we'll get you in' and I was quite impressed with that, especially when you know the pressure that the NHS is under." (UC, male, age 60)

\section{Reasons for retaining a preference for a fixed system of appointments}

Despite the fact that, as indicated by the quantitative findings, most expressed a preference for the new system, this was not always the case. While most people preferred the new system, a number actively expressed a wish for the old system and/or continued to use the old system of appointments. Some people who were initially introduced to the open access system subsequently requested to revert to the old system or were advised by the consultant that they could use both in tandem. In two instances the open access system had not been introduced as it should have been by the consultant.

"He normally made an appointment for me to go back and see him but he also said any time I wanted to make an appointment then phone his secretary and she would make me one. But I try to run between each appointment rather than do that - I try my best ..." (CD, male, age 52) 
Some individuals considered that the transfer of the onus onto the patient in making a decision to access care might erode the sense of security and certainty which came with the routine appointment system.

"I like to go about every 2 months just to see and talk to somebody. I go every couple of months and I prefer someone to keep an eye on me-I feel reassured." (UC, female, age 67)

"Well I think [fixed appointments] ... it's just a check up. You may go along one day and he says you don't need to take that medication, or he may spot something - it's nice to have that check." (CD, male, age 41)

Some people also expressed a dislike of the assertiveness required to instigate an appointment or telephone assistance which accessed medical help directly and felt uncomfortable using the secretary as a mediator.

"Well, yes, I've got a number but I think there should be a nurse in attendance who we can talk to, you know-if you're a bit worried. I mean his secretary is really nice but she's only there for appointments and that, isn't she ...? (UC, female, age 68)

The lack of confidence expressed in getting the new arrangements to work was sometimes confirmed by the system failing to respond to an individual's request or to operate the open access arrangements as originally agreed. It was clear that, on occasion, some individuals lacked the confidence to negotiate directly with the system even when they had been able to identify the problem that they considered needed medical attention.

"And this lady on NHS Direct told me I must ring them and demand an urgent appointment and if not I must ring her back and tell her. Anyway, they did push me in at 12.20 the following day." (UC, female, age 68)

"He would just give me an appointment, sometimes it would be cancelled more than once and at one time it was as long as 6 months. I do have his secretary's number but when I rang she just said 'no we haven't got any [appointments]'." (CD, female, age 29)

Finally, there was also some suggestion from the interviews that these individuals tended to feel less in control of their illness.

"I tend to suffer more at night which is partly my fault-I am trying to get myself into a routine now where I eat more during the day-every couple of hours I am supposed to have something to eat and one of my drinks to get the body used to eating and having food in it. But a lot of the time, because you feel so 'shitty' during the day-your stomach's hurting, you feel sick, you're on the toilet until dinner time or whatever-you do not physically feel you can eat anything because you feel you are going to bring it back up so sometimes I'm not eating till 6 o'clock at night. I know I've lost a lot of weight and I need to put some on so what do you do-not eat and lose more weight, or eat and suffer in the morning-you don't know what to do for the best." (CD, female, age 29)

\section{DISCUSSION}

The aim of this study was to explore the experiences of patients of modifying access arrangements as part of a new approach to managing illness. Preference for the new open access system was based on a sense of enhanced personal control in contacting services and the view that it fitted better with everyday routine management and the requirement for urgent medical contact when symptoms fail to respond to medication. Some people preferred to keep the fixed appointment system because of the sense of security this engendered. A limitation of the study is the extent to which it is possible to generalise from the experiences of access arrangements reported here to the use of health service access arrangements elsewhere and for different conditions. One fruitful avenue of future qualitative research would be to compare changing access arrangements across different service contexts and conditions.
The way in which the open access arrangements worked was, to a large degree, dependent on patients feeling able to self-refer based on their own evaluation of need. Compared with the previous system of fixed appointments, the findings suggested that many people felt able to do this once this option had been explained to them by their consultant. Satisfaction with the open access arrangements was based on the achievement of a closer fit between the ways in which people wished to exercise greater control in their everyday management of IBD and the decision to seek medical advice and input as a safety net system when self-management options had been exhausted. These findings suggest that the benefits of open access arrangements identified by respondents are likely to fit with the philosophy and principles of contemporary patient participation initiatives. The Expert Patients Programme ${ }^{13}$ which includes a self-management education training initiative is designed to improve people's confidence and ability to self-manage and engage in collaborative shared decision making with health professionals.

However, despite the fact that most of the patients preferred the new system, there was a preference among some patients for retaining the fixed appointment system. This was based on the need for a predictable and reliable system which was independent of the requirement to articulate the need for assistance on the part of the individual. In some instances this was a result of direct experience of a failure of organisational arrangements to respond to an individual's requests for assistance made under the open access system.

The underlying reasons for people's preferences need to be seen in the broader context of the way in which outpatient departments have traditionally determined arrangements for appointments, people's orientations towards health services, and the style with which they manage their own illness. Previous research suggests that appointment making is a complex social process where outcomes are negotiated..$^{14}$ In this study the use or otherwise of the open access system was not simply a matter of patients choosing one system over another. The consultants were able to influence the ability of patients to use open access arrangements by the extent to which they decided that such a system was appropriate for particular individuals and the extent to which they communicated and set up arrangements with other parties working within the outpatient department. In this respect, open access represents a paradox given that the move towards a more independent and patient driven system came initially from a relatively dependent doctor-patient relationship in which the consultants granted patients "permission" to use the new system. The relevance of this relationship is evidenced in the decision by a small minority of consultants to ignore the request to introduce these new arrangements or to offer both in tandem.

Intermediaries such as secretaries also assume a discretionary role in determining access to medical staff. ${ }^{15}$ At times it seems that the "gate keeping" activities of this group may have resulted in the failure to facilitate requests made through the open access system. Given the dependence of people on outpatient departments to administer and facilitate patient initiated requests for appointments, it is understandable that some people felt more able than others to assert their needs for an appointment and to negotiate this with hospital personnel. An implication of this is that, when the introduction of open access arrangements is being considered, there is a need to address the way in which access and appointment systems in outpatients have traditionally been centred on hospital and health staff routines (including those of secretarial and receptionist staff) and the ways these can be changed in a manner which is likely to 


\section{Key messages}

- There is an interaction between people's experience of health care and their subsequent use of services and illness management strategies.

- People make judgements about new access arrangements based on their comparison with existing arrangements for outpatients' appointments, and the extent to which people find that the new arrangements work in practice.

- An open access system is preferred by patients because of its opportunities for autonomy in making a decision to consult, the closer fit it has with illness trajectories, everyday routines and coping strategies for managing symptoms.

- An expressed preference for retaining fixed appointments is predicated on the perceived availability of planned and certain access which does not rely on patient initiation.

inspire and encourage confidence in patients to use the new system. Even when this is achieved, it is likely that there will be a role for retaining some access to fixed appointments alongside open access arrangements in order to meet expressed patient choice and to be able to respond to the different ways in which people wish to manage their condition and use the health service.

\section{ACKNOWLEDGEMENTS}

The authors are grateful to the patients who agreed to be interviewed, without whom this study would not have been possible, and to the investigators who were involved in the main trial (Dr Chris Roberts and Professor David Thompson, University of Manchester; Professor Mark Sculpher and Dr Gerry Richardson, University of York).

\section{Authors' affiliations}

A Rogers, A Kennedy, E Nelson, National Primary Care Research and Development Centre, The University of Manchester, Manchester M13 9PL, UK

A Robinson, Department of Medicine, Hope Hospital, Salford M6 8HD, UK

Funding: Health Technology Assessment Board. The National Primary Care Research and Development Centre is funded by the Department of Health. The views in this paper are those of the authors. The guarantor accepts full responsibility for the conduct of the qualitative study, had access to the data, and controlled the decision to publish.

\section{Competing interests: none}

$A K, A R$ and ARob were involved in the design of the qualitative study. $E N$ conducted the interviews. AR, AK and EN undertook the analysis and interpretation of results. AR and $A K$ drafted the paper. AK, ARob, and $A R$ were grant holders. $A R$ is the guarantor.

\section{REFERENCES}

1 Bury M. Chronic illness as a biographical disruption. Sociol Health Illness 1982;4:167-82.

2 Williams G. The genesis of chronic illness: narrative reconstruction. Sociol Health Illness 1984;6:175-200.

3 Von Korff M, Gruman J, Schaefer J, et al. Collaborative management of chronic illness. Ann Intern Med 1997; 127:1097-102

4 O'Cathain A, Munro JF, Nicholl JP, et al. How helpful is NHS Direct? Postal survey of callers. BMJ 2000;320:1035.

5 Hassell K, Whittington Z, Cantrill J, et al. Managing demand: transfer of management of self limiting conditions from general practice to community pharmacies. BMJ 2001;323:146-7.

6 Pencheon D. Intermediate care. BMJ 2002;324:1347-8.

7 Department of Health. Hospital activity statistics. http://www.doh.gov.uk/ hospitalactivity/statistics/2001-02/outpatient_attendances/q2/y00.htm, 2001.

8 British Society of Gastroenterology. Clinical practice guidelines: inflammatory bowel disease, British Society of Gastroenterology, 1996.

9 Williams JG, Cheung WY, Russell IT, et al. Open access follow up for inflammatory bowel disease: pragmatic randomised trial and cost effectiveness study. BMJ 2000;320:544-8.

10 Robinson A, Wilkin D, Thompson DG, et al. Guided self-management and patient-directed follow-up of ulcerative colitis: a randomised trial. Lancet 2001;358:976-81.

11 Glaser B. Advances in the methodology of grounded theory: theoretical sensitivity. Mill Valley: Sociology Press, 1978.

12 Richards T, Richards L. The NUDIST qualitative data analysis system. Qualitative Sociol 1991;14:307-24.

13 Department of Health. The expert patient: a new approach to chronic disease management in the 21 st century. London: The Stationery Office, 2001.

14 Gallagher M, Pearson P, Drinkwater C, et al. Managing patient demand: a qualitative study of appointment making in general practice. Br J Gen Pract 2001;51:280-5.

15 Arber S, Sawyer L. The role of the receptionist in general practice: a 'dragon behind the desk'. Soc Sci Med 1985;20:911-21.

16 Kennedy AP, Nelson E, Reeves D, et al. RCT to assess the impact of a package comprising a patient orientated, evidence based self-help guidebook and patient centred consultations on disease management and satisfaction in IBD. Health Technol Assess 2003;7.

17 Kennedy A, Rogers A. Improving self-management skills: a whole systems approach. Br J Nurs 2001;10:734-7.

18 Mansfield JC, Tanner AR, Bramble MG. Information for patients about inflammatory bowel disease. J R Coll Physicians Lond 1997:31:184-7.

19 Kennedy AP, Robinson A. A handy guide to managing ulcerative colitis. Southampton: RTFB Publishing, 2002.

20 Kennedy AP, Robinson A. A handy guide to managing Crohn's disease. Southampton: RTFB Publishing, 2000.

21 Kennedy AP, Robinson JA, Thompson DG, et al. Development of a guidebook to promote patient participation in the management of ulcerative colitis. Health Soc Care Community 1999;7:177-86.

22 Rogers A, Entwistle V, Pencheon D. A patient led NHS: managing demand at the interface between lay and primary care. BMJ 1998;316:1816-9. 